\title{
The Effect of Planning on Accuracy in Verbal Agreement in L2 Oral Performance
}

\author{
Hongbo Qi ${ }^{1}$ \\ ${ }^{1}$ Eastern Institute of Technology Data Science and Communication College, Zhejiang Yuexiu University, \\ Zhejiang, China \\ Correspondence: Hongbo Qi, Eastern Institute of Technology Data Science and Communication College, \\ Zhejiang Yuexiu University, Zhejiang, China.
}

Received: January 18, 2022

Accepted: February 14, 2022

Online Published: February 16, 2022

doi: 10.5539/elt.v15n3p22

URL: https://doi.org/10.5539/elt.v15n3p22

\begin{abstract}
Accuracy is widely recognized as one of the main dimensions in evaluating task-based oral performance. Indicators of accuracy vary in the literature of the effects of pre-task planning on the oral production. Enlightened by previous studies in pre-task planning and third-person singular $-s$, this article intends to find out whether the rate of suppliance of thematic verbal agreement increases as a result of pre-task planning, and whether the rate of suppliance of thematic verbal agreement in third-person singular $-s$ increases as a result of pre-task planning. A case study is carried on one subject who makes oral descriptions of a same graph which shows the number of people at London underground station from 6:00 to 22:00 on two separate occasions. The results of this study show that pre-task planning may have significant effect on accuracy of L2 oral output in thematic verbal agreement as a whole, but it may not affect L2 learners in their use of third-person singular -s.
\end{abstract}

Keywords: accuracy, oral performance, pre-task planning, thematic verbal agreement, third-person singular $-s$

\section{Introduction}

Accuracy is one of the dependent variables that are discussed in most studies in the effects of pre-task/strategic planning on the oral performances (Bygate, 1996; Wigglesworth, 1997; Mehnert, 1998; Foster \& Skehan, 1999; Ortega, 1999; Sangarun, 2005; Kawauchi, 2005; Kim, 2012; Vasylets, Gilabert, \& Manchon 2017; Aubrey, Lambert, \& Leeming, 2020; Stroud, 2021; Park, 2021; Sadeghi \& Mogaddam, 2021). Some discuss the effects of different lengths of time for planning on the oral discourse of L2 learners (for example, Mehnert, 1998), some explore the combined effects of proficiency and task types on accuracy (for example, Wigglesworth, 1997, Kim, 2012), others study the effects of proficiency on accuracy as a result of different planning types (for example, Kawauchi, 2005, Stroud, 2021), and still others investigate the effects of mode and task complexity on second language production. Recently, the effect of different planning conditions, different sources of pre-task planning on accuracy are also explored (Sadeghi \& Mogaddam, 2021; Park, 2021).

One prominent issue is, parameters in the measure of accuracy vary greatly in the literature. Articles, plural $-s$ marking, -ed marking, errors in 100 words, error-free T-unit/clauses, verbal morphology, etc. seem to be most widely used parameters in the measure of accuracy. While as a parameter of accuracy, inflected morpheme -ed is often discussed (Ortega, 1999; Kawauchi, 2005; Sadeghi \& Mogaddam, 2021), another important inflected morpheme, third person singular $-s$ is seldom mentioned in the literature.

Enlightened by Lardiere (1998a; 1998b) and Ionin and Wexler (2002) where the difficulty of grasping inflected morpheme for L2 learners is suggested, this study explores the effects of pre-task planning on the use of inflected morpheme, especially third person singular $-s$, by an advanced learner Amy (pseudo-name). As was suggested by Ionin and Wexler (2002), suppletive inflection be is much easier to be acquired than affixal inflections -s. In light of that, the suppliance of suppletive be is excluded in the current study, and Amy's use of third-person singular $-s$ is focused on. Meanwhile, considering the fact it might be possible that learners of English produce utterance such as "we goes to school at 8 every morning" in spoken language, thematic verbal agreement is also taken into consideration. Two research questions of this study are: (1) Does the rate of suppliance of thematic verbal agreement increase as a result of pre-task planning? (2) Does the rate of suppliance of thematic verbal agreement in third-person singular $-s$ increase as a result of pre-task planning? 
The article is made up of the following sections. In the second section, research in the effects of pre-task planning in recent decades is presented in terms of accuracy of oral performance of L2 learners. The third section introduces the purpose, the method and the results of this study, followed by a discussion in section four. A conclusion is drawn in section five based on the case study.

\section{Researches in the Effects of Pre-Task Planning on Accuracy of Oral Performance of L2 Learners}

In order to explore the effects of task repetition on oral production, Bygate (1996) analyzes the language produced by one learner narrating a video extract on two separate occasions immediately after viewing it. The indicators he adopts in representing the learner's accuracy are lexical selection/collocation and overall errors. He identifies 16 inappropriate expressions in Time 1 and 8 in Time 2; meanwhile, he also classifies 6 more appropriate expressions in Time 1 and 18 in Time 2. He then suggests that "the speaker's choice of vocabulary seems more native-like on the second occasion" (ibid, p. 143). As for overall errors, Bygate calculates the percentage of errors in Time 1 and Time 2, and concludes that "fewer errors would occur in Time 2" (ibid, p. 142) though as he acknowledges that the margin of improvement is quite small.

Mehnert (1998) explores the effects of different lengths of time for planning on speech production by L2 German learners. She divides 31 learners (intermediate level) into four groups, the control group has no planning time available, the three experimental groups have 1,5,10 minutes of planning time respectively before they start speaking. Each subject is assigned with two tasks in which he/she is asked to leave a message on a friend's answer machine. Both (instruction and exposition) tasks require the oral production of monologues. The measures Mehnert employs are the percentage of error-free clauses, the number of errors per 100 words, word order and lexical choice order. The results show that "accuracy of speech improved with only 1 minute planning but did not increase with more planning time" (ibid, p. 83).

In a comparatively more complicated study, Wigglesworth (1997) investigates the correlation between proficiency and task type in planned oral performance. She compares the transcriptions of 56 candidates in two proficiency levels (28 high and 28 low proficiency learners), and points out that high-proficiency group are significantly advantaged by planning time in the most difficult tasks in the accuracy of their use of verbal morphology while low-proficiency group are not advantaged by planning time in any task in the accuracy of their use of verbal morphology (ibid, p. 101). The measures for accuracy in this study are morphology (including plural $-s$, verb morphology) and articles. Both measures are calculated in terms of target-like or nontarget-like usage.

In a study aimed at disclosing whether planning helps learners focus on form in L2 oral performance, Ortega (1999) summarizes SLA studies on pre-task planning, and points out that the two difficulties in attempting to establish clear-cut patterns are "the lack of intercoder reliability" and "the lack of overlap or consistency in the measures used" (ibid, p. 113).

Based on the above review, Ortega (1999) employs Noun-modifier TLU (Target-like Use) and Article TLU as measures for accuracy. Once again, she finds that the relationship between planning and accuracy remains uncertain: "the difference in favor of planning on the TLU of the noun-modifier agreement was significant, whereas the difference in the mean TLU of the article system between the two conditions was not" (ibid, p. 126).

Enlightened by previous studies such as the ones by Wigglesworth (1997) and Ortega (1999), Kawauchi (2005) studies not only the effect of proficiency on L2 learners' oral performances, but also the effect of proficiency on oral performances of the same group of learners as a result of different types of strategic planning. To measure accuracy, the author uses the past tense markers for copula be, auxiliary verbs, regular verbs, and irregular verbs. It is interesting that the results of this study show that low EFL group benefit most from the opportunity to plan in the case of accuracy, challenging the results by Wigglesworth (1997), who claims that in the case of accuracy, planning might have the greatest effect on advanced level learners.

Vasylets, Gilabert, and Manchon (2017) investigate the effects of mode (oral vs. written) and task complexity on second language (L2) performance. 78 Catalan/Spanish learners of English are enlisted, with half of the participants performing the simple and complex versions of an argumentative, instruction-giving task orally, and the other half in writing. The results indicate that learners produce more idea units in speaking but more subordination, mean length of analysis-of-speech units, lexical diversity, extended idea units, and time on task in writing. As for the measure of accuracy, errors are identified and the total number of errors per 100 words are calculated, while spelling and punctuation errors in writing are not taken into account.

In order to examine the effects of three task conditions on teenage EFL learners' oral performance of a picture prompted task and their grammatical knowledge gain, Sadeghi and Mogaddam (2021) randomly assigned 34 
EFL learners into three experimental groups, namely online planning, pre-planning, and explicit instruction, and one control group. The parameters for accuracy in this study are Error-free clauses and Correct verb forms. The findings demonstrate that "explicit instruction may lead to better accuracy of the oral production" (ibid, p. 15).

It is therefore not difficult to draw a preliminary conclusion that there is no widely accepted measure for accuracy in the literature of the relationship between pre-task planning and oral performance. Articles, plural $-s$ marking, -ed marking, errors in 100 words, error-free T-unit/clauses, verbal morphology, etc. are all possible options, yet one can never be exhaustive about all the parameters. While there is still much to be done to set up a framework of measures for accuracy in L2 oral performance, verbal morphology seems to have become one of the most important indicators of accuracy. However, the term "verb morphology" covers a wide range of grammatical subcategories. As is reviewed above, most studies in the literature of accuracy either focus on affixal inflection -ed, or suppletive inflection be. It seems that very few (if any) employ another affixal inflection $-s$ (third-person singular) as a measure for accuracy in the study of pre-task planning. This study is mainly designed to find out whether pre-task planning affect the suppliance of third-person singular $-s$ in the oral output of L2 learners. In order to present a clearer picture of the issue, thematic verbal agreement as a whole is also included in the study.

\section{The Current Study}

\subsection{Purpose of the Study}

Lardiere (1998a; 1998b) carried out a 9-year longitudinal study on Patty, an adult Chinese speaker of L2 English who had been living in the USA for nearly 19 years and had been fully exposed to L2 English-speaking environment for at least eight-and-a-half years since the first recording (three in all). Patty's rate of using of -ed marking in obligatory context in all three recordings was as low as approximately $34 \%$. Still worse was the fact that she was using $-s$ marking between $0 \%$ and $4.76 \%$ in the meantime. A note needs to be added here is that all three recordings were done without planning. In another study by Ionin and Wexler (2002), who studied speech samples from 20 L1 Russian children who were living in the USA or Canada and acquiring/learning English there, suppletive inflection be is much easier to be acquired by the children than affixal inflection -s.

As one might argue that simple past tense is more robust in English, but that does not mean simple present tense is not important. While many studies focused on -ed marking in simple past tense, few (if any) has discussed the use of third-person singular $-s$ marking in simple present tense. When we discuss the use of $-s$ marking, we should not only investigate the suppliance of it in obligatory context, but also take into consideration the misuse of it in a context when nonfinite thematic verb is needed. Based on the above presumption, the purpose of this study is to find out (1) whether the rate of suppliance of thematic verbal agreement increases as a result of pre-task planning; and (2) whether the rate of suppliance of thematic verbal agreement in third-person singular $-s$ increases as a result of pre-task planning. Accordingly, two hypotheses are made: (1) The rate of suppliance of thematic verbal agreement increases as a result of pre-task planning; and (2) The rate of suppliance of thematic verbal agreement in third-person singular $-s$ increases as a result of pre-task planning.

\subsection{Method}

\subsubsection{The Participant}

The participant Amy (pseudo-name) in this study is an MA student in TEFL (Teaching English as a Foreign Language) of the Department of Linguistics and English Language, Lancaster University. Amy had learned English in China for at least10 years (6 years in secondary school, 4 years as an English major in a leading university in China) before studying at Lancaster University. She scored 7 in IELTS (6 in oral test) and by the time she participated in this study, she had been in the U.K. for more than 6 months. She is easy-going, active, and talkative. Compared with other participants in the literature, Amy can be regarded as an advance learner of English.

\subsubsection{Materials}

The data collected for this study were two digital recordings of oral exposition of a same graph by Amy on two separate occasions. The graph showed the number of people at London underground station from 6:00 to 22:00, Amy was asked to exposit the same graph twice: the first time she was not given any time to prepare, and the second time she was given 10 minutes preparation before speaking. This task was selected firstly because it is a demanding task for advanced learners of English as it is actually similar to task one of IELTS writing test, and therefore, whether an advanced learner is advantaged by planning time in the most difficult tasks in accuracy as stated by Wigglesworth (1997) can be testified. Secondly, this task was given in order to elicit usage of simple 
present tense in grammar, and thereupon, whether the rate of suppliance of verbal agreement (including $-s$ marking) improves as a result of planning can be found.

\subsubsection{Procedure}

Kawauki pointed out that most of the previous studies have attempted to examine planning effects by provide 10 minutes (Kawauki, 2005, p. 145), Though he tried three different types of planning activities, namely, writing, rehearsal, and reading, he could not find any distinctive effects pertaining to the three types of planning (ibid, $\mathrm{p}$. 160). Enlightened by Kawauki (2005) and Bygate (1996), the author of this study firstly asked the participant Amy to exposit the graph in the first recording without preparation, and then three days later, in the second recording (She did not know what she was supposed to do in the second time by the end of the first recording), she was given the same graph and was told to prepare for 10 minutes before speaking. She was allowed to write down everything she wanted, but was told that she could not look at the notes while she was speaking (as Kawauki, 2005 did). Lastly, she was asked to fill out a questionnaire which was designed in order to find out what the participant was thinking and doing while planning.

Amy's oral output was recorded with the help of a digital recorder and was then transferred the audio file into a computer. Employing a software called Soundscriber, Amy's recordings were transcribed in written format.

As Amy has good pronunciation, there seemed nothing unclear in transcribing. No immediate repetition in thematic verbs occurred. According to Ionin and Wexler (2002), suppletive inflection be is much easier to be acquired by the children than affixal inflections $-s$. The same may be true for adult L2/EFL learners. Therefore, this study examined suppliance in all obligatory occasions for (1) thematic verbal agreement; (2) thematic verbal third-person singular $-s$. The results of the calculation were double-checked by a colleague. In situations where the author and his colleague could not agree with each other, they resort to another colleague for intermediation. The transcriptions of the two recording are shown in Table 1.

Table 1. Transcriptions of the recording of the task by Amy in unplanned and planned conditions

\begin{tabular}{|c|c|}
\hline Time 1 (unplanned) & Time 2 (Planned) \\
\hline $\begin{array}{l}\text { This graph showed number of people at a } \\
\text { London underground station from } 6 \text {, maybe pm, } \\
\text { yes } 6 \text { pm to, er, } 22 \text { oh, no, no, } 6 \text { am to } 22 \mathrm{pm} \text {. } \\
\text { Um. I can see the first, um, at six o'clock there } \\
\text { are } 100 \text { people in the station. Um, as time goes, } \\
\text { the er, at } 8 \text { o'clock the the station have the time } \\
\text { have most of people it's about } 400 \text { people at the } \\
\text { station. And from } 8 \text { to } 10 \text {, the people, um, the } \\
\text { number of the people declined to um, maybe } 180 \\
\text { people at } 10 \text { o'clock. And from } 10 \text { to } 12 \text { the } \\
\text { number people um, gradually um, increased } \\
\text { from } 180 \text { to um, maybe, } 280 \text {, then the number } \\
\text { um, stay, um, on stable then on um, at from } 2 \\
\text { pm to, um, } 4 \text { pm, the number of people declined } \\
\text { again from er, } 300 \text { people to um, about } 100 \\
\text { people. And from um, } 4 \text { pm to um, } 6 \text { pm the } \\
\text { people, um, increased again. I think it's because } \\
\text { um, old people, um back from work to their } \\
\text { home. And from } 6 \text { to } 8 \text {, the people, the number } \\
\text { of people declined again, because all of them } \\
\text { um, stay at home with friend, um, yes. Um, then } \\
\text { the interesting thing is, from } 8 \text { to } 9 \text {, the people, } \\
\text { um, slowly increased within the, er, } 100 \text { and } \\
\text { 200. and again, last, in the last hour from } 9 \text { to } 10 \\
\text { the people declined again, yes, from about } 200 \\
\text { to } 100 \text {. yes, that's all. [2' } 42 \text { '] }\end{array}$ & $\begin{array}{l}\text { So this graph show, er, the, average number in an } \\
\text { under station at London. Um, it shows } 6 \text {, or no, } 16 \\
\text { hours from um, } 6 \text { am to um, to } 22 \text { pm. So there are um, } \\
\text { several noticeable increase and um, decline of } \\
\text { numbers. First is from } 6 \text { am to } 8 \text { am, the number } \\
\text { increase dramatically from } 100 \text { to } 400 \text {, because people, } \\
\text { um, lot of people um, goes out for work, and from } 8 \text { to } \\
10 \text {, the number declined because most people in their } \\
\text { office or stay at home. And from } 10 \text { am to um, to } 2 \\
\text { pm, this period of time, the number increased } \\
\text { gradually, because people, um, goes out for, it's lunch } \\
\text { time, people goes out to the restaurants, or, or, they go } \\
\text { home. Er, and from } 2 \text { pm to } 4 \text { pm, the number declined } \\
\text { again, because this is a work time again, most people } \\
\text { stay in their office or at their home, and from } 4 \text { pm to } 6 \\
\text { pm, this is a second dramatic increase showed in this } \\
\text { graph, um, yes, because, um, this is a time most people } \\
\text { um, end their work, and they went to the station, use } \\
\text { the subway to um, to go home. And from } 6 \text { pm to } 8 \\
\text { pm, the number um, decline dramatically because most } \\
\text { people will stay at home, um enjoying their supper or } \\
\text { yeah, stay at with their families. And from } 8 \text { pm to } 9 \\
\text { pm, there is a little increase um, between } 100 \text { to } 200 \\
\text { because maybe a part of people want to go out for } \\
\text { entertainment they will go to a club or bar or } \\
\text { something. And from } 9 \text { to } 10 \text { pm, the number declined } \\
\text { again. So that's the, what the graph show. That's all. } \\
\text { [2'57"] }\end{array}$ \\
\hline
\end{tabular}




\subsection{Results}

\subsubsection{The Rate of Suppliance of Thematic Verbal Agreement}

Table 2 gives the results of SOC (Supplied in Obligatory Contexts) analysis of thematic verbal agreement. The reason why SOC is applied instead of TLU is that in verbal agreement, there can hardly be situations in which the suppliance of inflected morpheme that is "target-like", instead of "correct" or "incorrect". As can be seen, there is only one corrected suppliance of verbal agreement in obligatory context (7.69\%) in Amy's unplanned recording, but the number rises to seven $(33.33 \%)$ when she is given 10 minutes' planning. Both the significant rise in number and rate shows that strategic planning has a positive effect on Amy's use of thematic verbal agreement, albeit the figure (33.33\%) is still low. Therefore, the first hypothesis of the study that the rate of suppliance of thematic verbal agreement increases as a result of pre-task planning is supported.

Table 2. SOC analysis of thematic verbal agreement

\begin{tabular}{lll}
\hline & Unplanned & Planned \\
\hline Number of suppliance in obligatory contexts & 1 & 7 \\
Total number of obligatory contexts & 13 & 21 \\
Percentage of suppliance over all obligatory contexts & 7.69 & 33.33 \\
\hline
\end{tabular}

\subsubsection{The Rate of Suppliance of Thematic Verbal Agreement in Third-Person Singular - $s$}

Table 3 shows the results of SOC analysis of thematic verbal agreement in third-person singular $-s$. As can be seen, Amy did not benefit much from the planning in her correct suppliance in third-person singular $-s$ since she supplied only one correct use (8.23\%) in her first recording while got all nine suppliances wrong in obligatory contexts $(0.00 \%)$ in her second recording. Thereupon, the second hypothesis that the rate of suppliance of thematic verbal agreement in third-person singular $-s$ increases as a result of pre-task planning is rejected.

Table 3. SOC analysis of thematic verbal agreement in third-person singular $-s$

\begin{tabular}{lll}
\hline & Unplanned & Planned \\
\hline Number of suppliance in obligatory contexts & 1 & 0 \\
Total number of obligatory contexts & 12 & 9 \\
Percentage of suppliance over all obligatory contexts & 8.33 & 0.00
\end{tabular}

\subsubsection{What the Participant was Doing and Think}

Table 4 illustrates the result of the questionnaire immediately after the second recording for Amy. The participant rated 4 for Item 4 , indicating that she felt the task demanding in unplanned condition, thus the assumption that the task is demanding for advanced learners is confirmed. Her answers to Item 1, 2 and 3 show that Amy was busy rehearsing during the time of planning; but her attention was mainly drawn to meaning (vocabulary) rather than on form (grammar).

Table 4. Result of the questionnaire

\begin{tabular}{lll}
\hline Statements & Degree in agreement \\
\hline 1 & When I was planning, I rehearsed what I was going to say. & 5 \\
2 & When I was planning, I thought about vocabulary a lot. & 4 \\
3 & When I was planning, I thought about grammar a lot. & 2 \\
4 & When I was planning, I thought about pronunciation a lot. & 2 \\
5 & When I was planning, I was careful about using third-person singular $-s$. & 2 \\
6 & I think the unplanned task demanding. & 4 \\
7 & I think the planned task demanding. & 3 \\
\hline
\end{tabular}

Note: $1=$ strongly disagree, $2=$ disagree, $3=$ neither agree nor disagree, $4=$ agree, and $5=$ strongly agree.

\section{Discussion}

The fact that both the number and rate of correct suppliance in obligatory contexts when Amy was not given time to plan in Table 2 is quite low seems hard to understand, yet this is a result of thematic verbal agreement, excluding all correct suppliance of agreement in be copula and be auxiliary, which are much easier for language 
learners to acquire. Once she is given 10 minutes and allowed to write down everything she likes before the second recording, Amy shows much progress in the use of correct verbal agreement. What's more, she uses more thematic verbs (21 in the second recording as compared to 13 in the first recording), showing that she really benefits quite a lot not only in accuracy but also in complexity (as far as more thematic verbs are used) from a 10-minute plan, which echoes the results of previous studies in the literature that advanced learners will benefit significantly from pre-task planning in more demanding tasks.

The results of Table 3, however, are very different from that of Table 2. Amy's suppliance of thematic verbal agreement in third-person singular $-s$ seems "decreased" as a result of planning, but with only one correct use in third-person singular in the first recording, this "finding" seems to be devalued. However, the results of Table 3 do not prove, at least, that the rate of suppliance of thematic verbal agreement in third-person singular $-s$ increases as a result of pre-task planning. Compared with Patty in the studies by Lardiere (1998a; 1998b), this result is by no means astonishing. In the 9-year longitudinal study, Patty's suppliance of -ed marking stabilized at about $34 \%$, her use of $-s$ marking remained at $0 \%$ to 4.76 . One might argue that Patty was not given time to plan, but it might be argued that the suppliance of $-s$ marking among Chinese learners might be a kind of stabilization or fossilization of grammar in verbal agreement. A few days after the second recording, Amy was interviewed on telephone and asked how she could explain her use of verbal agreement in the second recording. She said she might have prepared something during the planning time, but forgot them while speaking.

The results of the questionnaire immediately after the second recording firstly reveals an important fact that when Amy was planning (she was asked to write down everything she liked to write), she was also busy rehearsing (Item 1). Kawauchi defines three types of planning activity, namely, writing, rehearsal, and reading (2005: 146) and claims they are quite different. While it might be true what he suggests, Kawauchi fails to point out that at least two types of planning might occur coincidently. It may be more realistic that when one is writing or reading while planning, he/she is also rehearsing what he/she is going to say at the same time. The second important information based on Amy's responses to Item 2 and 3 is that Amy seems to be more focused on meaning rather than on form while planning. This might be another reason why (1) she made significant progress in thematic verbal agreement as a whole, but the percentage of suppliance over all obligatory contexts still remained quite low (33.33\%); (2) she made almost no progress in using $-s$ marking. The fact that Amy thought the task was demanding is important for the whole design of the study: A demanding task for an advanced Chinese learner of English in either unplanned or planned condition.

\section{Conclusion}

The results of this article are drawn from a case study of but one subject; therefore, they may not be the same in other cases. However, it does shed light on the effects of pre-task planning on accuracy of L2 oral output in that (1) it explores the effects of planning on accuracy in simple present verbal agreement; (2) it also discloses a fact that accuracy of the oral output might be far more complicated than it appears to be.

The results of the effects of planning on accuracy in verbal agreement are two-folded: pre-task planning has a positive effect on correct use of thematic verbal agreement as a whole, but does little to affect the correct suppliance of third-person singular $-s$. The results of the study may have been tricky if we only take the perspective of all thematic verbal agreement, or if we approach to the results of correct suppliance of third person singular $-s$ alone.

Wigglesworth's (1997) claim that high-proficiency group are significantly advantaged by planning time in the most difficult tasks in the accuracy of their use of verbal morphology may be true in this study as far as the correct suppliance of verbal agreement is concerned. However, both the results of Kawauchi (2005) and this study in the correct suppliance of third-person singular show the above claim may not necessarily the case.

While it seems that much needs to be done to set up a widely accepted framework of the measure for accuracy of L2 oral output, the results of this study disclose two important facts: (1) pre-task planning may have significant effect on accuracy of L2 oral output in thematic verbal agreement as a whole; and (2) pre-task planning may not affect L2 learners in their use of third-person singular $-s$. It is hoped that this case study on Amy will arouse more interest in the study of accuracy as well as the use of third-person singular $-s$ as a result of pre-task planning.

\section{References}

Aubrey, S., Lambert, C., \& Leeming, P. (2020). The impact of first as opposed to second language pre-task planning on the content of problem-solving task performance. Language Teaching Research, 1-26. https://doi.org/10.1177/1362168820917844 
Bygate, M. (1996). Effects of task repetition: Appraising the developing language of learners. In J. Willis \& D. Willis (Eds.), Challenge and change in language teaching. Oxford: Heinemann.

Foster, P., \& Skehan, P. (1999). The influence of source of planning and focus of planning on task-based performance. Language Teaching Research, 3(3), 215-247. https://doi.org/10.1177/136216889900300303

Ionion, T., \& Wexler, K. (2002). Why is 'is' easier than '-s': acquisition of tense/agreement morphology by child second language learners of English. Second Language Research, 18(2), 95-136. https://doi.org/10.1191/0267658302sr195oa

Kawauchi, C. (2005). The effects of strategic planning on the oral narratives of learners with low and high intermediate L2 proficiency. In R. Ellis (Ed.), Planning and task performance in a second language (pp. 143-164). Philadelphia: John Benjamins Pub. Co. https://doi.org/10.1075/11lt.11.09kaw

Kim, Y. (2012). Effects of pretask modeling on attention to form and question development. TESOL Quarterly, 47(1), 8-35. https://doi.org/10.1002/tesq.52

Lardiere, D. (1998a). Case and tense in the 'fossilized' steady state. Second Language Research, 14(1), 1-26. https://doi.org/10.1191/026765898674105303

Lardiere, D. (1998b). Dissociating syntax from morphology in a divergent end-state grammar. Second Language Research, 14(4), 359-375. https://doi.org/10.1191/026765898672500216

Mehnert, U. (1998). The effects of different lengths of time for planning on second language performance. Studies in Second Language Acquisition, 20(1), 83-108. https://doi.org/10.1017-/s0272263198001041

Ortega, L. (1999). Planning and focus on form in L2 oral performance. Studies in Second Language Acquisition, 21(1), 109-148. https://doi.org/10.1017/S0272263199001047

Park, M. S. (2021). Effects of Different Sources of Pre-task Planning on Second Language Oral Performance A Study of Korean EFL Learners. TESL-EJ, 25(2), 1-16. Retrieved from https://files.eric.ed.gov/fulltext/EJ1314678.pdf

Sadeghi, K., \& Mogaddam, A. H. (2021). The Effect of Different Planning Conditions versus Explicit Grammar Instruction on Teenage EFL Learners' Oral Production of a Picture Promoted Task and Grammar Gain. Research Square. https://doi.org/10.21203/rs.3.rs-658851/v1

Sangarun, J. (2005). The effects of focusing on meaning and form in strategic planning. In R. Ellis (Ed.), Planning and task performance in a second language (pp. 111-141). Philadelphia: John Benjamins Pub. Co. https://doi.org/10.1075/11lt.11.08san

Stroud, R. (2019). The effects of strategic planning and rehearsal on second language group discussion task $\begin{array}{lllll}\text { performance. The Language Learning } & \text { 2-14. }\end{array}$ https://doi.org/10.1080/09571736.2019.1610475

Vasylets, O., Gilabert, R., \& Manchon, R. M. (2017). The effects of mode and task complexity on second language production. Language Learning, 67(2), 394-430. https://doi.org/10.1111/lang.12228

Wigglesworth, G. (1997). An investigation of planning time and proficiency level on oral test discourse. Language Testing, 14(1), 85-106. https://doi.org/10.1177/026553229701400105

\section{Copyrights}

Copyright for this article is retained by the author(s), with first publication rights granted to the journal.

This is an open-access article distributed under the terms and conditions of the Creative Commons Attribution license (http://creativecommons.org/licenses/by/4.0/). 